\title{
FORMAÇÃO CONTINUADA NO ESPAÇO ESCOLAR: UMA ANÁLISE DAS DISSERTAÇÕES E TESES DEFENDIDAS NO ESTADO DE SÃO PAULO
}

\author{
CONTINUED TRAINING IN SCHOOL SPACE: AN ANALYSIS OF \\ DISSERTATIONS AND THESES DEFENDED IN THE STATE OF SÃO PAULO
}

\author{
FORMACIÓN CONTINUADA EN EL ESPACIO ESCOLAR: UN ANÁLISIS DE LAS \\ DISERTACIONES Y TESIS DEFENDIDAS EN EL ESTADO DE SÃO PAULO
}

\author{
Edson do Carmo Inforsato \\ UNESP, FCLAr \\ E-mail: tamoyo@fclar.unesp.br \\ Flávia Graziela Moreira Passalacqua \\ UNESP, FCLAr \\ E-mail: flaviagraziela@hotmail.com
}

\begin{abstract}
RESUMO
O presente artigo focaliza a formação continuada de professores dos anos iniciais do Ensino Fundamental, analisando as ações formativas que são realizadas dentro do espaço escolar, a partir do levantamento das dissertações e teses produzidas nos Programas de Pós-graduação em Educação situados no estado de São Paulo. Sendo assim, apresenta um panorama dos estudos sobre a temática desde a década de 1990, enfatizando o crescente aumento das pesquisas no decorrer dos anos, sendo alicerçadas principalmente na vertente reflexiva e colaborativa como rebate ao paradigma da racionalidade técnica. Contudo, apesar do consenso em torno da modalidade formativa, suas ações demonstram ser incipientes quanto a sua efetividade no atendimento as reais necessidades de formação dos professores.
\end{abstract}

Palavras-chave: Formação continuada de professores; Necessidades formativas; Anos iniciais do Ensino Fundamental

\begin{abstract}
This article focuses on the continuing education of teachers from the initial years of Elementary School, analyzing the formative actions that are performed within the school space, based on the survey of the dissertations and theses produced in the Graduate Programs in Education located in the state of São Paulo. Thus, it presents a panorama of the studies on the subject since the 1990s, emphasizing the increasing increase of research over the years, being based mainly on the reflexive and collaborative side as a rebate to the paradigm of technical rationality. However, in spite of the consensus regarding the formative modality, its actions demonstrate to be incipient as to its effectiveness in attending to the real needs of the formation of the teachers.
\end{abstract}


Key words: Continuing education of teachers; Training needs; Early Years of Elementary Education

\section{RESUMEN}

El presente artículo se centra en la formación continuada de profesores de los años iniciales de la Enseñanza Fundamental, analizando las acciones formativas que se realizan dentro del espacio escolar, a partir del levantamiento de las disertaciones y tesis producidas en los Programas de Postgrado en Educación situados en el estado de São Paulo. Por lo tanto, presenta un panorama de los estudios sobre la temática desde la década de 1990, enfatizando el creciente aumento de las investigaciones a lo largo de los años, siendo fundadas principalmente en la vertiente reflexiva y colaborativa como rebate al paradigma de la racionalidad técnica. Sin embargo, a pesar del consenso en torno a la modalidad formativa, sus acciones demuestran ser incipientes en cuanto a su efectividad en la atención a las reales necesidades de formación de los profesores.

Palabras clave: Formación continuada de profesores; Necesidades formativas; Años iniciales de la Enseñanza Fundamental

\section{O QUE DIZEM AS DISSERTAÇÕES E TESES SOBRE FORMAÇÃO CONTINUADA DE PROFESSORES?}

A apreciação dos estudos (ANDRÉ, 2002; BRZEZINSKI, et al., 2006; BRZEZINSKI, 2014) referentes ao campo da formação de professores, assim como, a análise das dissertações e teses defendidas no período de 2000 a 2015, disponíveis para download em arquivo digitalizado nas Bibliotecas Digitais e Bancos de Publicações das IES situadas no estado de SP (PASSALACQUA, 2017), mostram que a produção discente, sobre a temática da formação continuada de professores vem aumentando consideravelmente no decorrer dos anos. Destacando a crescente preocupação com a qualidade da formação inicial e continuada dos professores a partir da década de 1990, ressaltando a modalidade de formação em serviço, devido a fatores como as políticas de valorização docente, o crescimento da capacitação e aprimoramento dos professores, transcorrendo da exigência de uma formação adequada para atender a complexidade do trabalho pedagógico contemporâneo, levando a necessidade de avaliação das ações formativas e, por consequência, gerando demandas e apreensões das instâncias governamentais e sociais quanto a efetividade da educação e do sistema de ensino (ROMANOWSKI, 2013).

A implantação de políticas públicas como a LDB n . 9394/96, garantindo a habilitação para atuação nos anos iniciais do Ensino Fundamental em nivel superior e o direito a formação continuada dos profesores (BRASIL, 2016), o Plano Nacional de Educação (BRASIL, 2001-2014) abordando as metas de ampliação dos programas de formação em 
serviço e a valorização dos profissionais da educação e a Resolução $\mathrm{n}^{\circ} .2$, de $1^{\circ}$ de julho de 2015 (BRASIL, 2015) definindo as Diretrizes Curriculares Nacionais para a Formação Inicial e para a Formação Continuada, expressando a necessidade de capacitar os professores para atender as diferentes demandas postas pela contemporaneidade, são fatores determinantes para a aceleração das pesquisas no campo da formação de professores, através de novas proposições teóricas inseridas no meio acadêmico, visando a avaliação e implantação dos cursos e programas formativos (ROMANOWISKI, 2013). Assim como, o ímpeto do momento histórico, caracterizado pelo aumento dos programas de Pós-Graduação em Educação no país, o conjunto de reformas políticas, as percepções de práticas pedagógicas, o rebate ao paradigma da racionalidade técnica e a valorização de ações formativas de colaboração e parceria (ANDRÉ, 2002; BRZEZINSKI \& GARRIDO, 2006; BRZEZINSKI, 2014).

De acordo com André (2002) no período de 1990 a 1996, de 284 dissertações e teses encontradas sobre formação de professores, apenas 42 (14,8\%) delas discutiam temas ligados a formação continuada, enquanto que no período de 1997 a 2002, Brzezinshi e Garrido (2006) relatam que foram localizados 1769 trabalhos discentes, porém foram selecionados 742 deles para compor a amostra de pesquisa, desse montante 115 (15\%) abordavam a temática da formação continuada de professores. Já no período de 2003 a 2007 foram encontrados 1167 trabalhos e destes foram selecionados para compor a mostra 574 deles, sendo que 78 (14\%) trabalhos equivalem a formação continuada e no período de 2008 a 2010 foram encontrados 1947 trabalhos, sendo selecionados 420 deles para compor a mostra de pesquisa, porém devido as dificuldades enfrentadas no decorrer do estudo foram analisados apenas 200 deles, sendo que 25 (12\%) debatem a formação continuada (BRZEZINSKI, 2014).

Observa-se nos estudos de Brzezinski e Garrido (2006) e Brzezinski (2014) a preocupação com o grande volume de publicações e a distância referente a relação espaçotempo para a análise dos textos, optando por selecionar algumas IES e PPGE distribuídos pelo território nacional e nos quais assumem a responsabilidade pela análise da própria produção discente. Dessa forma, no que se refere ao estado de São Paulo, foram selecionados os trabalhos produzidos nos Programas de Pós-Graduação em Educação da PUC-SP, UFSCar, UMESP e USP no período de 1997 a 2002 (BRZEZINSKI \& GARRIDO, 2006) e da PUCSP, UNESP de Presente Prudente e USP para o período de 2003 a 2007 e da PUC-SP e UNESP de Presidente Prudente para o período de 2008 a 2010 (BRZEZINSKI, 2014). 
No que diz respeito a formação continuada de professores, no período de 1990 a 1996, os estudos demonstraram ser incipientes, os aspectos focalizados são variados e bem distribuídos, abrangendo diferentes contextos, meios utilizados e níveis de ensino, apresentando resultados expressivos para a modalidade formativa, analisando propostas de Governo ou de Secretarias de Educação, programas ou cursos de formação, processos de formação em serviço e questões ligadas a prática pedagógica (ANDRË, 2002).

No período de 1997 a 2002 há um crescente aumento das publicações na área, podendo estar relacionada ao fato da temática ser uma das linhas teóricas do Pnud ${ }^{1}$, destacando a vertente curricular que envolve a formação presencial, semipresencial e a distância. (BRZEZINSKI \& GARRIDO, 2006). Segundo o levantamento, este momento foi marcado por uma transformação no paradigma que alicerçou os programas de formação continuada no final da década de 1990, deixando os modelos da racionalidade técnica, através de cursos de curta duração, treinamentos, capacitações, etc., para o predomínio do paradigma da complexa relação que envolve a Educação, a Universidade, a Sociedade do Conhecimento e o Mundo do Trabalho, perpassando pela dialética reflexiva, que fundamenta os programas que vislumbram as parcerias colaborativas (BRZEZINKI \& GARRIDO, 2006). Além disso, a análise dos trabalhos correspondentes, aponta investigações relacionadas a relatos de experiência, pesquisas de campo, pesquisas colaborativas interinstitucionais ou voluntárias, estudos avaliativos de programas ou projetos desenvolvidos por Secretarias de Educação ou organizados por Entidades Sindicais, parcerias institucionais entre Centros Formativos e Secretarias de Educação, pesquisas colaborativas centradas em escolas, pesquisas colaborativas entre pesquisadores e professores da Escola Básica - alusivas aos diferentes níveis de ensino (Educação Infantil, Ensino Fundamental, Ensino Médio, Ensino Técnico e Profissionalizante, EJA e Educação Especial) -, disciplinas curriculares (língua portuguesa, matemática, ciências, geografia, história, educação física e artes), temas específicos como escola rural, educação indígena, crianças de rua e prisão, pesquisas colaborativas entre pesquisadores no Ensino Superior, referentes a formação de formadores, disciplinas pedagógicas para cursos de engenharia e odontologia, pós-graduação stricto sensu, avaliação e impacto de programas e projetos com uso de novas tecnologias (BRZEZINSKI \& GARRIDO, 2006, p.20).

\footnotetext{
${ }^{1}$ Programa das Nações Unidas para o Desenvolvimento.
} 
Já no período de 2003 a 2010, verifica-se a evolução da formação continuada e uma ênfase na análise de propostas que envolvem o aprimoramento docente, o desenvolvimento de parcerias colaborativas e a importância da formação continuada realizada dentro do espaço escolar no exercício da função pedagógica como aspecto fundamental para o desenvolvimento profissional dos professores, assim como, a apreciação das lutas erguidas pelas entidades formativas após a promulgação da LDB 9394/96, para o estabelecimento de convênios que possibilitassem qualificar os professores no próprio local de trabalho (em serviço) ou em cursos que não exigissem o afastamento das atividades didáticas realizadas diariamente; por outro lado, a análise do período também evidenciou o pouco interesse dos discentes pela temática se comparado às categorias referentes a formação inicial e o trabalho docente que aparecem como os campos mais investigados ao longo dos anos nos PPGE (BRZEZINSKI, 2014). Outras áreas do conhecimento também demonstram o interesse na temática abordada através de investigações sobre a formação de professores no Ensino Superior tornando-se um campo de estudo emergente - graduação: Assistência Social, Formação Profissional $\left(\mathrm{Cefet}^{2}\right)$, Fisioterapia, Administração, Odontologia e Medicina; Pós-Graduação: Ciências Jurídicas, Letras, Matemática, Odontologia e Física. Além disso, são apontadas as avaliações de impacto dos programas e formações em $\mathrm{EaD}$ - não sendo mais considerada uma linha de investigação emergente - e a inclusão digital. Nota-se a presença inicial de estudos sobre formação continuada de professores do Ensino Médio, professores do Ensino Superior em Fisioterapia e de professores de cursos de Africanidades no Brasil (BRZEZINSKI, 2014).

Contudo, para Brzezinski (2014) o tema emergente para o campo da formação continuada é denominado de "andragogia" - um conceito educacional aferido à área que se dedica em pesquisar a Educação de Adultos - e tais estudos almejam dar sentido ao "ensino para adultos" (p.31). Outros temas referem-se ao autodidatismo no manejo computacional e ao impacto do ambiente colaborativo na formação de pesquisadores que atuam no Ensino Superior e em extensas investigações qualitativas com o auxílio de softwares. Também são estimadas como temáticas emergentes as relações existentes entre as políticas de avaliação institucional e as políticas de formação continuada de docentes do Ensino Superior, assim como, a formação de professores para a diversidade étnico-racial (BRZEZINSKI, 2014).

Por certo é relevante ressaltar que os levantamentos realizados demostram que as parcerias colaborativas "[...] denotam interesse das universidades, entidades acadêmicas, secretarias de educação, sindicatos de professores e pesquisadores individualmente

\footnotetext{
${ }^{2}$ Centro Federal de Educação Tecnológica.
} 
colaborativos" (p.31) focalizando o compromisso com a qualidade da docência na Educação Básica e no Ensino Superior a partir dos anos 2000 (BRZEZINSKI, 2014). Sendo assim, no que se refere ao estado de São Paulo, foram localizadas nas plataformas online e disponíveis para download, banco de publicações de teses e dissertações e bibliotecas digitais das IES e PPGE situados no referido estado 348 trabalhos, sendo 219 (63\%) de dissertações e 129 (37\%) de teses sobre formação continuada de professores no período de 2000 a 2015, sendo que $30(8,62 \%)$ desses trabalhos - $20(67 \%)$ correspondem as dissertações e $10(33 \%)$ as teses - referem-se especificamente a formação continuada na modalidade em serviço dos professores dos anos iniciais do Ensino Fundamental que foram realizadas in lócus, ou seja, dentro do espaço de atuação pedagógica, ou seja, dentro das escolas (PASSALACQUA, 2017).

Contudo, o aumento constante das pesquisas sobre formação continuada advém da ampliação da concepção de profissionais da educação, da diversidade de enfoques teóricos, da pluralidade de temáticas, da multiplicidade de experiências formativas que acabam refletindo nas modificações culturais da sociedade do conhecimento, educacional, cientifica e tecnológica, assim como, no mundo do trabalho e nas distintas formas de poder e do saber vivenciados ultimamente (BRZEZINSKI, 2014). De acordo com Passalacqua (2017) as pesquisas na área tenderão a crescer $10,5 \%$ em nível nacional e $23 \%$ em nível estadual até 2030, destacando a tradição das pesquisas educacionais no estado de São Paulo, iniciadas nas décadas de 1960 e 1970 através do desenvolvimento das atividades realizadas no Programa de Educação: Psicologia da Educação datado de 1969 da PUC-SP, o Programa de Educação: História, Política e Sociedade de 1971 e os Programas de Educação: Currículo e o de Educação Matemática de 1975 também da PUC-SP, o Programa de Educação da USP-SP de 1971 e o Programa de Educação da UFSCar de 1976. Por certo, à medida que o volume de estudos cresce, aumentam as dificuldades dos pesquisadores obterem o conhecimento do seu "estado da arte" ou "estado do conhecimento", devido as especificidades que envolvem a relação espaço/tempo, salientando a emergência de estudos nas modalidades com a união e envolvimento de pesquisadores e grupos de pesquisas voltados a tais investigações (BRZEZINSKI, 2014).

\section{O QUE REVELA A PRODUÇÃO DISCENTE SOBRE AS AÇÕES REALIZADAS NO ESPAÇO ESCOLAR?}


No levantamento das dissertações e teses no estado de São Paulo evidenciou-se que a UNESP possui o maior número de trabalhos sobre formação continuada de professores com $33 \%$ das publicações, sendo $20 \%$ de dissertações e $13 \%$ de teses, seguida da PUC-SP com $25 \%$, sendo $18 \%$ de dissertações e $7 \%$ de teses, em terceiro aparece a UNICAMP com 13\%, sendo $6 \%$ de dissertações e $7 \%$ de teses, seguida da USP-SP com 10\%, sendo $6 \%$ de dissertações e $4 \%$ de teses e da UFSCar com 10\%, sendo 5\% de dissertações e $5 \%$ de teses, seguidas da UNIMEP com 3\%, sendo $2 \%$ de dissertações e $1 \%$ de teses, em sétimo lugar aparece a CUML apresentando $2 \%$ das dissertações, seguida da PUCCAMP, UMESP, UNISO e USF representando 1\% cada uma das dissertações encontradas (PASSALACQUA, 2017. Entretanto, segundo Passalacqua (2017) existiram algumas dificuldades no acesso as páginas online das demais IES que mantém programas de pós-graduação em educação que impossibilitaram a consulta dos dados, destacando a não existência de Biblioteca Digital ou Banco de Publicações disponível para pesquisa das dissertações e teses defendidas nos seus respectivos PPGE, seja por demonstrarem estar em manutenção e/ou em fase de construção. Por outro lado, o Programa de educação da USP de Ribeirão Preto não apresentou publicações que se referissem ao descritor estudado. Esclarece-se que no estado de São Paulo existem cursos de Pós-Graduação em Educação que não foram utilizados pela mostra de pesquisa citada como, por exemplo, o Programa de Educação e Saúde da UNIMEP e o Programa de Educação nas Profissões da Saúde da PUC-SP, por estarem inclinados a outras áreas do conhecimento.

Embora, tenha-se o intuito de apresentar os dados referentes aos trabalhos que tratam de formação continuada realizada no espaço escolar para professores dos anos iniciais do Ensino Fundamental, esclarece-se que o conteúdo apresentado pelo montante de estudos levantados é variado e abrangente, apresentando temas relacionados a formação continuada de professores em serviço dentro do ambiente escolar, porém orientados a outros níveis de ensino (Educação infantil, Ensino Fundamental II, Ensino Médio, educação Especial e Ensino Superior) ou projetados para formação em serviço de coordenadores e/ou diretores sem o envolvimento dos professores, análises específicas de programas e projetos de formação continuada provenientes das Secretarias de Educação e análise de políticas públicas de formação continuada, bem como, os reflexos da formação continuada na prática pedagógica e pequenos balanços de publicações. Ressalta-se que a maior parte dos trabalhos levantados centralizam suas análises em especificidades dos programas e projetos de formação 
continuada propostos pelas Secretarias de Educação e nos quais, são realizados fora do espaço escolar (PASSALACQUA. 2017).

No que se refere aos estudos sobre a formação continuada de professores dos anos iniciais dentro do espaço escolar, a amostra obtida evidenciou que a UNESP também possui o maior número de publicações, representando 33\% das publicações, sendo $23 \%$ das dissertações e 10\% das teses selecionadas, seguida da PUC-SP representando $30 \%$ das publicações, sendo $20 \%$ das dissertações e $10 \%$ das teses, em terceiro lugar aparece a UFSCar representando $23 \%$ das publicações, sendo $20 \%$ das dissertações e $3 \%$ das teses, em quarto lugar aparece a UNICAMP representando 7\% das teses selecionadas, em quinto lugar aparece a USP representando 3\% das teses, seguida da CUML e USF representando cada uma $2 \%$ das dissertações (PASSALACQUA, 2017). Através da seleção dos textos, buscou-se compreender o porquê que as ações de formação continuada em serviço ainda não produzem resultados satisfatórios na profissionalidade docente quanto ao suprimento/atendimento de suas necessidades formativas, pois segundo Passalacqua (2017) as ações formativas realizadas no espaço escolar possuem pouca efetividade, não melhoram o desempenho dos professores, assim como, não contribuem para o desenvolvimento profissional docente, pois elas não são baseadas em levantamentos criteriosos de necessidades formativas.

Dessa forma, a análise da produção discente evidenciou que por mais de três décadas a formação continuada em serviço vem se configurando como campo de investigação embasada nas metodologias colaborativas e abordagens teóricas que ilustram a escola e os professores como provedores de reflexão, além de realizarem análises sobre o cotidiano da prática pedagógica no Ensino Fundamental com o apoio dos pesquisadores das universidades, os saberes erguidos mutuamente, amparando as práticas e as ações formativas realizadas (PASSALACQUA. 2017). Demonstra-se uma predominância teórica das questões que abarcam a formação do professor no espaço escolar apresentando $22 \%$ dos registros encontrados na amostragem, seguida das demandas que abordam a prática reflexiva dos professores com $20 \%$ dos registros, da valorização dos saberes e da experiência docente apresentando $17 \%$ e do trabalho coletivo e colaborativo com $16 \%$ dos registros, por outro lado, apresentando uma menor predisposição teórica aparecem as necessidades de formação dos professores apresentando 9\% dos registros, as questões que abrangem os professores como sujeitos de sua própria formação com $7 \%$, a formação inicial e o estágio com $6 \%$ dos registros e o ciclo profissional dos professores com 3\% (PASSALACQUA, 2017). 
$\mathrm{Na}$ amostra evidencia-se um consenso teórico direcionado a prática reflexiva/coletiva e colaborativa, valorizando o saber e a experiência docente, ressaltando que as ações de formação continuada devem ser realizadas dentro do espaço escolar, no exercício da função docente e fundamentadas nas necessidades dos professores. Os autores mais citados nas investigações compõem um elenco diversificado, por conhecimento, no nível internacional os estudos fazem referência a John Dewey, Donald Shön, Kenneth Zeichner, Philippe Perrenoud, Philippe Meirieu, Maurice Tardif, Jacques Delors, Michael Huberman, Andy Hargreaves, Isabel Alarcão, Rui Canário, José Contreras, Carlos Marcelo Garcia, Francisco Imbernón, Antônio Nóvoa, José Pacheco, Angel Pérez Gómez, José Gimeno Sacristan, Juan Carlos Tedesco, Angela Rodrigues, Manuela Esteves, e no nível nacional fazem referência à Marli André, Vera Maria Candau, Paulo Freire, José Fusari, Bernadete Gatti, José Carlos Libânio, Alda Junqueira Marin, Maria da Graça Mizukami e Selma Garrido Pimenta(PASSALACQUA, 2017, p. 140). Contudo, alguns estudos estão inseridos de acordo com as perspectivas de autores específicos como, por exemplo, Pierre Bourdieu, Michel Foucault, Jürgen Habermas, Jean Piaget, Lev Vygotsky e Ana Teberosky, que, embora sejam autores de destaque nas suas respectivas áreas de conhecimento, não desenvolvem estudos sobre a temática da formação continuada de professores (PASSALACQUA, 2017).

No que se refere a fundamentação metodológica, os estudos são pautados em autores como Robert Bogdan e Sari Biklen, Michail Bakhtin, Laurence Bardin, Wilfred Carr e Stephen Kennis, René Barbier, Michel Thiollent, Maria Cecília Minayo, Menga Lüdke e Marli André, Ivana Ibiapina, Selma Garrido Pimenta e Carlos Rodrigues Brandão (PASSALACQUA, 2017, p. 141). Dessa forma, os estudos são descritos como estudos qualitativos e exploratórios, entretanto, também são referidos pelos autores como estudos qualitativos do tipo Estudo de Caso, Pesquisa-ação, Etnografia ou com características da Etnografia, Investigação-colaborativa, Pesquisa colaborativa, Construtivo-colaborativo de pesquisa intervenção, Investigação narrativa e Pesquisa participante. Nesse aspecto, salientase uma maior atenção na leitura integral dos textos, pois como alerta Brzezinski (2014):

[...] os próprios autores não descreviam com a precisão necessária os contextos, os cenários e os contornos do estudo; os sujeitos pesquisados; o método; a metodologia; os procedimentos, os instrumentais e as técnicas de pesquisa adotadas [...] (p.106).

Observa-se nos estudos as dificuldades dos autores para descreverem e definirem precisamente a metodologia de suas investigações, pois as opções metodológicas inicialmente 
projetadas são normalmente reorganizadas ao longo das pesquisas, devido aos percalços enfrentados no decorrer das investigações. Os estudos alicerçados na metodologia da pesquisa-ação apresentam ser os mais prejudicados (PASSALACQUA, 2017), pois esbarram nas especificidades dos contextos pesquisados, sofrendo alterações e exigindo novos rumos para as pesquisas, salientando algumas das diferentes necessidades presentes nos contextos escolares (RODRIGUES \& ESTEVES, 1993) e que podem estar escondidas nas especificidades das diferentes culturas existentes nas escolas (HARGREAVES, 1998). Entretanto, as opções metodológicas dos estudos seguem a abordagem da pesquisa na formação de professores (BORTONI-RICARDO, 2008; PIMENTA, 2005, NÓVOA, 1992) nos quais existe a compreensão de que os professores são construtores de conhecimentos a partir da reflexão crítica sobre a sua atividade dentro da escola, também podendo facilitar a inserção de pesquisadores na instituição escolar e a participação dos docentes em grupos de pesquisa.

Em relação aos instrumentos utilizados nas investigações, os estudos apresentam que os pesquisadores optam pela utilização de mais de um recurso para compor a coleta de dados de suas pesquisas, sendo as opções aceitas com maior frequência a associação entre a observação mais a entrevista mais o questionário, a observação mais a entrevista, a observação mais o questionário e a observação mais a entrevista e/ou questionário mais os demais registros obtidos em campo como: os registros de reuniões, ferramentas digitais e recursos audiovisuais. Embora a variedade de fontes para coleta de dados empregadas indique a amplitude das demandas que abarcam a formação continuada de professores, as opiniões e representações que constituem a base desses recursos podem implicar em circunscritas apreciações (PASSALACQUA, 2017). Além disso, nota-se na amostragem uma presença muito pequena dos pesquisadores no campo investigado para a realização das observações, comparecendo de três a cinco vezes no ambiente escolar para detectar as dificuldades que os docentes encaram em suas salas de aula e/ou o desenvolvimento e avaliação de ações formativas realizadas na escola, podendo não evidenciar as reais necessidades dos professores e não confirmar significativamente a efetividade das ações formativas e sim questões específicas que são vivenciadas em um espaço de tempo relativamente curto. Contudo, os pesquisadores ressaltam as dificuldades enfrentadas no percurso das investigações, esbarrando nas especificidades do cotidiano das escolas e do não cumprimento do cronograma de atividades formativas, determinando ajustes para coleta de dados e reformulações das metodologias de pesquisa (PASSALACQUA, 2017). 
Os assuntos explorados nos trabalhos incidem com maior frequência na formação centrada na escola e no ensino de matemática, representando cada um $20 \%$ dos assuntos abordados na amostra, seguidos de educação especial, TIC's e saberes e competências pedagógicas, representando cada um 10\% dos estudos, ensino de ciências e as necessidades de formação, correspondendo cada um a 7\% dos estudos e alfabetização, coordenação pedagógica, educação musical, ensino de história e professor iniciante indicam cada um 3\% dos estudos. Os temas predominantes para as ações de formação continuada realizadas dentro do espaço escolar são orientados para o desenvolvimento do currículo, visto que $46 \%$ dos estudos referem-se ao ensino de matemática, ensino de ciências, ensino de história, alfabetização, educação musical e TIC's (PASSALACQUA, 2017). No entanto, esta constatação representa um avanço na concepção de formação continuada pois deixa de apresentar "[...] um conjunto de ações dispersas para ter foco direcionado à proposta curricular, ou seja, para o cumprimento das expectativas de aprendizagem" (GATTI, BARRETO \& ANDRÉ, 2011, p. 199).

Quanto as ações formativas, elas são apresentadas em poucos trabalhos e projetadas seguindo os pressupostos reflexivos, coletivos e colaborativos, no entanto, sua realização ainda carece de fundamentos para se caracterizar plenamente como pesquisa-ação-intervenção (PASSALACQUA, 2017). Os estudos apresentam uma queixa quase que absoluta dos pesquisadores em relação a falta de espaços apropriados para se conduzir as ações formativas, ocorrendo sempre em locais improvisados e desocupados por curtos períodos, sendo direcionados para a biblioteca, laboratório, refeitório, sala de informática, sala de vídeo e mesmo outra sala de aula. No caso das ações realizadas em HTPC/ATPC as atividades devem ocupar apenas uma parcela do tempo destinado as reuniões, deixando a outra parte do horário reservado para os assuntos específicos tratados pela equipe gestora.

Além disso, as ações formativas possuem o intuito de trabalhar com as necessidades dos docentes, entretanto, seu levantamento é realizado por meio de questionários iniciais, entrevistas e pequenos momentos de observação em sala de aula. Entretanto, enfatiza-se que tais instrumentos são captadores das necessidades dos professores, porém devem ser bem conduzidos e atrelados a outros (PASSALACQUA, 2017). A entrevista e o questionário são muito utilizados no levantamento das necessidades, mas podem apresentar lacunas no diagnóstico ao não demonstrarem, por exemplo, as necessidades inconscientes ${ }^{3}$ dos

\footnotetext{
${ }^{3}$ Necessidades inconscientes são as frustrações, anseios e vontades que não são percebidas e não são sentidas pelos sujeitos/professores como pessoas e não são manifestadas no coletivo. 
professores (RODRIGUES, 2006; GALINDO, 2011), assim como, a observação de campo sendo empregada em curtos espaços de tempo (GALINDO, 2011). Neste aspecto, salienta-se que a observação de campo é primordial no levantamento das necessidades de formação dos professores (GALINDO (2011), pois conforme a investigação avança, os vínculos entre pesquisadores e professores são estabelecidos, suprindo os empecilhos vivenciados entre a suposta vigília do pesquisador às práticas pedagógicas dos professores, revelando as reais necessidades (PASSALACQUA, 2013) e ressaltando a sua característica empírica (GALINDO. 2011)

No entanto, destaca-se que as ações formativas que apresentam melhores resultados são aquelas fundamentadas em projetos de intervenção-ação centrados nas dificuldades que os professores enfrentam no dia-a-dia das instituições escolares, sendo as ações mais expressivas desenvolvidas em longos períodos de formação e com apoio externo e as de maior relevo aquelas que abarcam o coletivo ou centram-se em práticas específicas dos docentes (ESTRELA, 2001). Sendo assim, segundo Estrela (2001) essas ações formativas [...] "levam a concluir que as mudanças de práticas exigem tempo e acompanhamento prolongado antes que os formandos conquistem a sua plena autonomia" (p.41). Da mesma forma, Davis, et al (2011-2012) revelam que independente da abordagem adotada para o cumprimento das ações de formação continuada de professores, as modalidades que proporcionam os melhores resultados são aquelas mais sistematizadas, com atividades regulares e realizadas no local de exercício da função pedagógica. Sendo assim, a amostragem indica que as ações formativas presentes nos estudos são incipientes, pois possuem o intuito de formar os docentes em serviço ao atender as suas necessidades, porém apresentam falhas na composição das ações e estratégias formativas ao serem efetuadas em curtos períodos e lacunas no levantamento das necessidades, estruturando as atividades formativas em palestras, cursos de curta duração e reuniões técnicas-reflexivas sobre temas específicos e de interesse comum no grupo de professores (PASSALACQUA, 2017), deixando à deriva fatores essenciais para seu diagnóstico e entendimento como as diferentes fases da carreira docente (HUBERMAN, 2000), os saberes adquiridos ao longo da profissão (TARDIF, 2011) e a presença das diferentes culturas profissionais existentes nas escolas (HARGREAVES, 1998), assim como, as necessidades pessoais ${ }^{4}$ dos professores (RODRIGUES \& ESTEVES, 1993).

\footnotetext{
${ }^{4}$ As necessidades pessoais são as expectativas, aspirações, frustrações, etc. dos indivíduos como pessoas.
} 
Contudo, no que se refere ao planejamento e desenvolvimento conjunto das ações formativas entre pesquisadores e professores dos anos iniciais, a amostragem não permite definir o grau de envolvimento e participação dos docentes da educação básica devido a abordagem colaborativa, ressaltando uma maior pré-disposição dos pesquisadores ao buscarem os conteúdos e organizarem as formações em torno de processos reflexivos, assim promovendo os trabalhos colaborativos. Por outro lado, reforça-se a queixa sobre a falta de preparo dos professores e os limites apresentados pela modalidade, expondo a necessidade de investimento na formação profissional dos professores (PASSALACQUA, 2017).

Dessa forma, a amostragem permite recomendar que a formação de professores deva ser pensada como um aprendizado sucessivo ao longo da vida, conjugado aos ciclos profissionais (HUBERMAN, 200) e aos saberes edificados durante a trajetória profissional (TARDIF, 2011), implicando no envolvimento dos docentes em ações e estratégias bem estruturadas, longas e delineadas em torno do atendimento das necessidades formativas. Entretanto, os estudos também indicam que as ações formativas que são fundamentadas em estruturas colaborativas acabam deslizando nas especificidades das instituições escolares, provenientes das questões internas e externas à escola, decorrendo em resistências dos professores para acolherem tais propostas e, consequentemente, resultando em processos reflexivos e colaborativos falaciosos (FULLAN \& HARGREAVES, 2000), nas quais são derivadas das estratégias de contorno que os docentes constituem e que são amparadas nos saberes adquiridos com a experiência pedagógica (SCANFELLA, 2013). Assim, evidenciando as diferentes formas de oposição apresentadas pelas necessidades, como a dualidade entre as necessidades pessoais e as sistêmicas ${ }^{5}$, o contraste entre as necessidades conscientes $^{6}$ e inconscientes e o embate entre as necessidades particulares ${ }^{7}$ e coletivas ${ }^{8}$ (PASSALACQUA, 2017).

Os estudos também indicam que apesar dos professores apresentarem a formação adequada a legislação através da obtenção da licenciatura em nível superior (BRASIL, 2016), demonstrando que $6 \%$ dos participantes das pesquisas possuem apenas o magistério e $94 \%$ deles possuem habilitação para atuar nos anos iniciais do Ensino Fundamental através da graduação em pedagogia, normal superior, outra licenciatura ou formação em nível superior

\footnotetext{
${ }^{5}$ Necessidades sistêmicas são aquelas oriundas do sistema ou organização institucional.

${ }^{6}$ Necessidades consciente são aquela percebidas e sentidas pelos sujeitos como pessoas e dentro do coletivo.

${ }^{7}$ Necessidades particulares são aquelas sentidas e manifestadas por um único sujeito de determinado grupo de pessoas.

${ }^{8}$ Necessidades coletivas são aquelas que estão presentes no conjunto de pessoas de um determinado contexto.
} 
através de programas de formação em serviço, salientando que $26 \%$ deles possuem formação em cursos de pós-graduação em níveis lato sensu e stricto sensu, ainda é destacada a insuficiência da formação inicial ao não proporcionar a aquisição de saberes plurais, provenientes dos saberes disciplinares e curriculares, orientando a construção dos saberes adquiridos com a experiência a partir de um fazer pedagógico reflexivo (TARDIF, 2011; TARDIF \& RAYMOND, 2000; PASSALACQUA, 2017). Portanto, enfatiza-se que os saberes disciplinares e curriculares necessitam ser adquiridos durante a trajetória da formação inicial através da integração realizada entre a teoria e a reflexão crítica sobre a atividade prática e a realidade cotidiana das escolas (TARDIF, 2011).

Neste aspecto, constatou-se a existência de problemas curriculares nos cursos de licenciatura ao evidenciar uma constante crítica dos professores quanto a carência de formação nos conteúdos das disciplinas específicas, como matemática, ciências e história, assim como, a lacuna em torno da temática da inclusão social e digital, sinalizando que a insuficiência de aprofundamento teórico/prático dos conteúdos durante a graduação implica diretamente na qualidade das práticas pedagógicas que serão realizadas pelos futuros professores e realçando as necessidades formativas que surgem durante essa etapa da carreira. Entretanto, tais aspectos enfatizam que as necessidades formativas dos professores são compostas desde a formação inicial, seja através da significativa lacuna curricular referente aos conteúdos e métodos, pela concepção meramente instrumental da didática ou compreensão (consciência) da didática fundamental, através da exposição da realidade vivenciada nas escolas e os diferentes problemas que deverão ser encarados por eles no exercício da profissão (CANDAU, 1997; PASSALACQUA, 2017). ${ }^{9}$

Sendo assim, a amostra de pesquisa enfatiza por um lado os problemas cotidianos e as distintas necessidades dos professores e por outro lado, destaca os limites da formação continuada e a ascensão do discurso da formação em serviço centrada no espaço escolar, evidenciando um abismo entre as ações formativas desenvolvidas e o atendimento/suprimento das reais necessidades dos professores. Neste sentido, nota-se que mesmo com o avanço das últimas décadas, com as políticas de formação docente e as pesquisas educacionais, a formação continuada ainda desponta como um grande desafio para se obter bons resultados.

\footnotetext{
${ }^{9}$ Segundo Candau (1997) a didática instrumental é um conjunto de técnicas e habilidades que os docentes devem conter para que se tenha um ensino eficiente e a didática fundamental, parte da análise e compreensão das relações escola-sociedade, estando articulada às diferentes abordagens educacionais, projetos político-sociais e embasados na perspectiva da construção de uma sociedade democrática.
} 
Assim, concluindo que mais de trinta anos de consenso crítico quanto ao paradigma da racionalidade técnica e didática instrumental, os estudos demonstram que até o momento houve pouco avanço quanto a qualidade da formação docente, advertindo que "[...] sem melhorar a formação inicial, não há como melhorar a formação continuada (PASSALACQUA, 2017, p. 184). Indicando a emergência de estudos empíricos sobre formação continuada em serviço (in lócus), abrangendo o campo das necessidades formativas dos professores e amparados nas diferentes fases da carreira, realizando levantamentos criteriosos através de instrumentos mais precisos, pois ainda existe uma carência de estudos na área.

\section{REFERÊNCIAS}

ANDRÉ, M. E. D. A. (Org.) Formação de professores no Brasil (1990-1998). (Série Estado do Conhecimento). Brasília: MEC/Inep/Comped, 2002.

BORTONI-RICARDO, S. M. O professor pesquisador: introdução à pesquisa qualitativa. São Paulo: Parábola Editorial, 2008.

BRASIL. Conselho Nacional de Educação/Conselho Pleno. Resolução $\mathbf{n}^{\circ} \mathbf{2}$, de $\mathbf{1}^{\mathbf{0}}$ de julho de 2015. Define Diretrizes Curriculares Nacionais para a formação inicial em nível superior (cursos de licenciatura, cursos de formação pedagógica para graduados e cursos de segunda licenciatura) e para a formação continuada. Brasília, DF, 2015.

BRASIL. Ministério da Educação. Secretaria de Educação Básica. Secretaria de Educação Continuada, Alfabetização, Diversidade e Inclusão. Conselho Nacional da Educação. Diretrizes Curriculares Nacionais Gerais da Educação. Brasília: MEC, SEB, DICEI, 2013.

Lei 10.172, de 09 de janeiro de 2001. Aprova o Plano Nacional de Educação e dá outras providências. Diário Oficial da União. Brasília, DF, 2001. Disponível em: <http://www.planalto.gov.br/ccivil_03/leis/leis_2001/110172.htm>. Acesso em: 01 nov 2016.

Lei Darcy Ribeiro (1996). LDB: Lei de Diretrizes e Bases da Educação Nacional: Lei $\mathrm{N}^{\circ}$. 9.394, de 20 de dezembro de 1996, que estabelece as diretrizes e bases da educação nacional. 12a . ed. Brasília: Câmara dos Deputados, Edições Câmara, 2016. - (Série legislação; n. 254).

BRZEZINSKI, I. Formação de profissionais da educação (2003-2010). Brasília: Instituto Nacional de Estudos e Pesquisas Educacionais Anísio Teixeira, 2014. (Série Estado do Conhecimento, ISSN: 1676-0565; n.13)

BRZEZINSKI, I; GARRIDO, E. Formação de profissionais da educação (1997-2002). Brasília: Ministério da Educação, Instituto Nacional de Estudos e Pesquisas Educacionais Anísio Teixeira, 2006. (Série Estado do Conhecimento, ISSN 1676-0565; n.10). 
CANDAU, V. M. Da didática fundamental ao fundamental da didática. In: ANDRÉ, M. E. D. A. ; OLIVEIRA, M. R. N. S. (orgs.) Alternativas do ensino de Didática. Ed. Papiros. Campinas/SP, 1997. p. 71-95.

DAVIS, C. L. F.; NUNES, M. M. R.; ALMEIDA, P. C. A.; SILVA, A. P. F.; SOUZA, J. C. Formação continuada de professores: uma análise das modalidades e das práticas em estados e municípios brasileiros. (Coleção Textos FCC, 34). FCC/DPE. São Paulo, 2012.

Formação continuada de professores em alguns estados e municípios do Brasil. Cad. Pesquisa. vol.41, n.144, pp.826-849, 2011.

ESTRELA, M. T. Realidades e perspectivas da formação contínua de professores. Revista Portuguesa de Educação, Universidade do Minho, Braga, Portugal, vol. 14, núm. 1, p.27-48, 2001.

FULlAN, M.; HARGREAVES, A. A Escola como Organização Aprendente: buscando uma organização de qualidade. Trad. Regina Garcez. $2^{a}$.Ed. Porto Alegre: Artes Médicas Sul, 2000 .

GALINDO, C. J. Análise de necessidades de formação continuada de professores: uma contribuição às propostas de formação. 2011. 384 f. Tese (Doutorado em Educação Escolar) Faculdade de Ciências e Letras, Universidade Estadual Paulista. Araraquara, 2011.

HARGREAVES, A. Os professores em tempos de mudança. O trabalho e a cultura dos professores na idade pós-moderna. Amadora: Editora Mcgraw-Hill de Portugal, 1998.

HUBERMAN, M. O ciclo de vida profissional dos professores. In: NÓVOA, A. (Org.). Vidas de professores. Porto: Porto Editora, 2000. p. 31-62.

NÓVOA, A. Formação de professores e profissão docente. In: NÒVOA. A.(Org.). Os professores e sua formação. Lisboa: Dom Quixote, 1992. p.13-33.

PASSALACQUA, F. G. M. Necessidades pessoais e coletivas de professores dos anos iniciais do ensino fundamental: um estudo qualitativo em busca de estratégias de formação continuada em serviço. 2013. 153 f. Dissertação (Mestrado em Educação Escolar) - Faculdade de Ciências e Letras, Universidade Estadual Paulista. Araraquara, 2013.

PIMENTA, S. G. Pesquisa-ação crítico-colaborativo: construindo seu significado a partir de experiências com a formação docente. Educ. Pesq., São Paulo, v.31, n.3, 2005.

RODRIGUES, A. Análise das práticas e de necessidades de formação. Lisboa: Direção Geral de Inovação e de Desenvolvimento Curricular, 2006.

RODRIGUES, A.; ESTEVES, M. A Análise de necessidade na formação de professores. Portugal: Porto Editora, 1993.

ROMANOWSKI, J. P. Tendências da pesquisa em formação de professores. Atos de Pesquisa em Educação - PPGE/ME. (ISSN 1809-0354). v. 8, n. 2, p.479-499, mai./ago. 2013. Disponível em: http://dx.doi.org/10.7867/1809-0354.2013v8n2p479-499> Acesso em: 08 nov 2016. 
SCANFELLA, A. T. Mudanças na alfabetização e resistência docente na "voz" de professoras dos anos iniciais do ensino fundamental: implicações das medidas políticas na prática pedagógica. Dissertação de Mestrado. Araraquara: Faculdade de Ciências e Letras, Universidade estadual Paulista, 2013.

TARDIF, M. Saberes docentes e formação profissional.12a .ed. Petrópolis, RJ: Vozes, 2011. 